\title{
Oxidation of organics in water in microfluidic electrochemical reactors: Theoretical model and experiments
}

\author{
Onofrio Scialdone*, Chiara Guarisco, Alessandro Galia \\ Dipartimento di Ingegneria Chimica, Gestionale, Informatica, Meccanica, Università di Palermo, Viale delle Scienze, 90128 Palermo, Italy
}

\section{A R T I C L E I N F O}

\section{Article history:}

Received 8 August 2011

Received in revised form

25 September 2011

Accepted 27 September 2011

Available online 5 October 2011

\section{Keywords:}

Micro devices

Micro reactors

Electrochemical oxidation

Wastewater treatments

BDD

Theoretical model

Sh number

\begin{abstract}
A B S T R A C T
The electrochemical oxidation of organics in water performed in micro reactors on boron doped diamond (BDD) anode was investigated both theoretically and experimentally in order to find the influence of various operative parameters on the conversion and the current efficiency CE of the process. The electrochemical oxidation of formic acid (FA) was selected as a model case. High conversions for a single passage of the electrolytic solution inside the cell were obtained by operating with proper residence times and low distances between cathode and anode. The effect of initial concentration, flow rate and current density was investigated in detail. Theoretical predictions were in very good agreement with experimental results for both mass transfer control, oxidation reaction control and mixed kinetic regimes in spite of the fact that no adjustable parameters was used. Mass transfer process was successfully modelled by considering for simplicity a constant $S h$ number (e.g., a constant mass transfer coefficient $k_{m}$ ) for a process performed with no high values of the current intensity to minimize the effect of the gas bubbling on the flowdynamic pattern. For mixed kinetic regimes, two different modelling approaches were used. In the first one, the oxidation of organics at BDD was assumed to be mass transfer controlled and to occur with an intrinsic $100 \%$ CE when applied current density is higher than the limiting current density. In the second case, the $C E$ of the process was modelled assuming that the competition between organic and water oxidation depends only on the electrodic material and on the nature and the concentration of the organic. In the latter case a better agreement between experimental data and theoretical predictions was observed.
\end{abstract}

(c) 2011 Elsevier Ltd. All rights reserved.

\section{Introduction}

Microsystems technology, coming from information technology and miniaturization of data-processing devices, has entered many fields in our daily life. In the last years microfluidic technology has been employed in various areas ranging from the food industry through biotechnology to pharmaceutical products, from analytical and laboratory scale equipment through energy conversion to industrial chemistry applications for the production of millions of tons of chemicals [1]. It has been shown that chemical reactions if performed in suitable microfluidic devices can benefit of enhanced heat and mass transfer, higher product yield, selectivity and purity, improved safety, access to new products and quite easy scale down, scale up or modularization of the processes [1,2].

Electrochemical microfluidic devices, realized by integration of electrodes in micro devices, were widely employed in the last years for analytical purposes [2,4-7]. These devices were also used for preparative purposes [3,5,8-10], for monitoring flow velocities

\footnotetext{
* Corresponding author. Tel.: +3909123863754.

E-mail address: onofrio.scialdone@unipa.it (O. Scialdone).
}

in microfluidic channels [11-14] or evaluating chemico-physical parameters such as diffusion coefficients and kinetic rate constants [15-17]. The authors have recently demonstrated that a flow cell with a micrometric distance between the cathode and the anode can be successfully used also to perform the electrochemical treatment of waters contaminated by organic pollutants [18].

Electrochemical processes are considered among the more promising for the treatment of waste waters contaminated by bio-refractory or toxic organic pollutants [19]. These methods are environmental friendly, involve very mild operative conditions (ambient temperature and atmospheric pressure), limited operative costs [20] and can oxidize toxic organic compounds effectively [19]. The effectiveness of the electrochemical treatment depends on many factors including the electrode material. Several anodic materials have been tested, but most of them presented important drawbacks such as a rapid loss of activity (graphite), release of toxic ions $\left(\mathrm{PbO}_{2}\right)$, limited service life $\left(\mathrm{SnO}_{2}\right)$, not complete or not efficient oxidation $\left(\mathrm{IrO}_{2}\right)[19,21,22]$. On the contrary, synthetic boron doped diamond (BDD), characterized by high anodic stability and wide potential window, allows the total oxidation of a large number of organic pollutants [22-24]. The electrochemical treatment of wastewaters contaminated by organic pollutants can 
strongly benefit from the utilization of microfluidic electrochemical reactors (e.g. cells with a distance between the cathode and the anode of tens or hundreds of micrometers). Thus, very small distances between electrodes lead from one side to a drastic reduction of the Ohmic resistances, thus allowing electrochemical incineration of organic pollutants with lower cell voltages and without supporting electrolyte [18], and on the other side to the intensification of mass transport of the pollutants to electrodes surfaces [18]. Please consider that in conventional cells, one needs adding to system a supporting electrolyte to achieve reasonable cell voltages when the medium does not present an adequate conductivity. This is certainly a main obstacle for a wide application of electrochemical abatement. Indeed, adding chemicals to a water stream is often a problematic issue, being opposed to general administrative regulations since this may lead to the formation of secondary pollutants during electrochemical incineration of organics, and anyway increases the operative costs. Mass transfer intensification is also a key point in these processes to increase current efficiencies and to decrease the durations of treatment since mass transfer rates towards electrodes are usually extremely reduced at the low pollutant concentrations required by regulations. The utilization of micro devices can furthermore offer other important advantages such as:

- Easier scale-up procedure through simple parallelization of many small units $[5,8,9]$.

- Fast screening of the effect of operative parameters. The small distances between electrodes allow very high conversions of the organic pollutants for a single passage of the water solution inside the cell, thus allowing continuous operation. As a consequence, a screening of the effect of operative parameters on the performances of the process can be performed in short times by fast changing of the steady state conditions in comparison to conventional macro systems that must operate in batch recycling mode.

- The possibility to operate in a continuous mode potentially allows the utilization of a multi stage system involving two or more cells operating in series with different applied current densities in order to maximize the current efficiency and to minimize the treatment times.

It follows that microfluidic apparatuses that otherwise present the drawback of a more facile fouling and clogging, can be potentially a very useful tool in the field of the electrochemical treatment of waters contaminated by refractant organic pollutants. In the present work, we have studied the effect of numerous operative parameters, such as the applied current density, the volumetric flow rate $\Phi_{V}$, the initial organic concentration and the distance between the electrodes, on the anodic oxidation of organics in water in order to individuate the optimal operative conditions. Formic acid (FA) was chosen as model substrate since it is a common intermediate or by-product of the oxidation of more complex organics and, as a consequence, it has been well studied in conventional electrochemical reactors [25-27,31]. Furthermore, the direct oxidation of this simple molecule is not expected to involve the formation of significant amounts of stable intermediates thus making easier the analysis of experimental results. BDD was selected as anode since this material presents an high oxygen overpotential and is probably among the more promising for the electrochemical abatement of organics [22,23].

The electrochemical process should be characterized by the complete removal of the organic pollutants with low treatment times and high current efficiencies. Quite often the high number of operative parameters, which may be adjusted makes an empirical investigation exceedingly onerous in order to individuate the conditions which allow to optimise the process. Hence theoretical predictions/mathematical models offer leading strategies to select the best experimental conditions to be tested. The experimental validation of mathematical models can, furthermore, confirm the assumptions on which the model is based and allows one to describe the process properly. For these reason, several models have been developed in recent years to describe the electrochemical treatment of wastewaters containing organic pollutants in conventional electrochemical reactors [24,26,28-32]. In the present work a simple theoretical model was proposed as an extension of previous models developed for the oxidation of organics in water in conventional cells [26,31]. to predict the effect of various operative parameters on the electrochemical oxidation of organics in microfluidic electrochemical reactors. To reduce the complexity of the model, the effect of bubble gas evolution on the flowdynamic pattern was not considered here. Thus, the developed model can be used only for not too high values of applied current intensity. On the other hand, this limitation is likely to be not so stringent at least in the environmental field when low concentrations of pollutants often arise leading to low values of applied current densities. Quite interestingly, a good agreement between theoretical predictions and experimental data was observed in spite of the fact that no adjustable parameter was used.

\section{Experimental}

Micro electrochemical cells were built upon inserting two or three polytetrafluoroethylene (PTFE) micrometric spacers in a commercial undivided filter press flow cell ElectroCell $A B$. The cell was equipped with two plate electrodes (wet surface $A \approx 2.7 \mathrm{~cm}^{2}$ ) of $\mathrm{BDD} / \mathrm{Nb}$ (Condias, Germany) and nickel, used as anode and cathode, respectively. Working and counter electrodes were separated by two or three PTFE spacers (Bohlender GmbH, Germany) with nominal thickness of $25 \mu \mathrm{m}$. Spacers were cut to define the wet area of parallepedic solution volume wetting each electrode (see Table 1 for details). Electrolyses were carried out under continuous mode using a syringe pump (New Era Pump Systems, Inc.) to feed solutions in the cell system at specified flow rates. Most of the experiments were performed by allowing a single passage of the electrolytic solution inside the cell. In few cases two passages were operated.

All electrolyses were driven by an Amel 2053 potentiostat/galvanostat operated exclusively in the galvanostatic mode at the following current intensities: 6, 9, 18, 27, 36, 54, 63, 72, 81, 90, 99 and $108 \mathrm{~mA}$. Samples of $1 \mathrm{ml}$ of the electrolytic solution were analyzed by high performance liquid chromatography (HPLC) to evaluate the performances of the process in terms of abatement of the acid and current efficiency. For each tested operative condition at least 4 samples were analyzed to be sure that steady state conditions were achieved. Very good reproducibility was usually observed after the first run. Liquid chromatographic analyses were performed with an Alltech Platinum EPS C18 column using a HP 1100 HPLC equipped with UV-vis detector (adopted wavelength $\lambda=210 \mathrm{~nm}$ ). A buffer solution containing $\mathrm{KH}_{2} \mathrm{PO}_{4}$ and $\mathrm{H}_{3} \mathrm{PO}_{4}$ at $\mathrm{pH}=2.5$ was used as mobile phase with an elution flow rate of $1 \mathrm{ml} \mathrm{min}^{-1}$.

The abatement (e.g., the conversion) of the organic $X$ and the current efficiency $C E$ were defined by Eqs. (1) and (2), respectively.

$X=\frac{c^{0}-c^{f}}{c^{0}}$

$C E=\frac{n F V c^{0} X}{i_{\mathrm{app}} A t}=\frac{n F c^{0} X \Phi_{V}}{i_{\mathrm{app}} A}$

where $c^{0}$ and $c^{f}$ are the initial and final concentrations of the organic inside the electrochemical cell, $n$ is the number of electrons exchanged for the oxidation of the organic $R H$ to carbon dioxide ( 2 
Table 1

Parameters used for the theoretical model.

\begin{tabular}{|c|c|c|c|c|}
\hline \multicolumn{2}{|c|}{ Geometric characteristics of the micro reactor } & \multicolumn{2}{|c|}{ Chemico-physical parameters of the organic pollutant ${ }^{\mathrm{a}}$} & \multirow{2}{*}{$\begin{array}{l}S h^{\mathrm{b}} \\
4.86\end{array}$} \\
\hline$L(\mathrm{~cm})$ & 10 & $D\left(\mathrm{~cm}^{2} / \mathrm{s}\right)$ & $10^{-5}$ & \\
\hline$W(\mathrm{~cm})$ & 0.27 & {$[R H]^{*}\left(\mathrm{mmol} \mathrm{dm}^{-3}\right)$} & 2.2 & \\
\hline$h(\mu \mathrm{m})$ & $50-75$ & & & \\
\hline
\end{tabular}

a From a study on the electrochemical incineration of formic acid in conventional filter-press electrochemical cell [26].

b From Ref. [39].

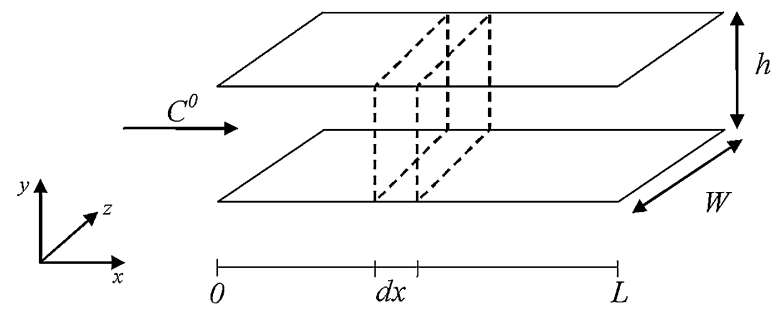

Fig. 1. Scheme of the micro channel. $h$ is the height of the channel which coincides with the distance between the electrodes, $W$ and $L$ are width and length of the channel (that coincide with width and length of the electrodes). $c^{0}$ is the concentration of formic acid at the cell entrance.

for formic acid) or to a stable compound, $F$ the Faraday constant $\left(96487 \mathrm{C} \mathrm{mol}^{-1}\right), i_{\text {app }}$ the applied current density, $t$ the average residence time of the solution in the cell, $V$ the volume of the cell and $\Phi_{V}$ the volumetric flow rate. In the presence of more organics, the abatement of the chemical oxygen demand of the solution COD (computed on a molar base) $X_{\mathrm{COD}}$ and the relative current efficiency $C E_{\text {COD }}$ are given by Eqs. (3) and (4), respectively.

$X_{\mathrm{COD}}=\frac{\mathrm{COD}^{0}-\mathrm{COD}^{f}}{\mathrm{COD}^{0}}$

$C E_{\mathrm{COD}}=\frac{n F C O D^{0} X_{\mathrm{COD}} \Phi_{V}}{i_{\mathrm{app}} A}$

where $\mathrm{COD}^{0}$ and $\mathrm{COD}^{f}$ are the initial and final COD inside the electrochemical cell.

Formic acid from Aldrich was used as substrate. $\mathrm{H}_{2} \mathrm{SO}_{4}$ (Sigma Aldrich) was used to achieve a $\mathrm{pH}$ of 2.

Theoretical predictions were realized using the parameters cited in Table 1. For the sake of simplicity the nominal thickness of the spacers was used as the distance between the electrodes. In fact, PTFE is a polymer with high cristallinity so that its compression is expected to be quite low. Furthermore, this approximation leads to a conservative estimation of conversions. Diffusion coefficient $D$ and $[R H]^{*}$ for formic acid were taken from a work on the electrochemical oxidation of FA in conventional filter-press type cells [26].

\section{Results and discussion}

\subsection{Principles and theoretical model}

As previously mentioned, one specific objective of this work is the development of a simple theoretical model for the electrochemical oxidation of organics in microfluidic reactors. Please note, however that most of the following considerations can be readily extended to the case of a reduction process. Oxidation can proceed directly to carbon dioxide (Eq. (5)) or by the formation of an intermediate I which presents a not negligible concentration in the reactor (Eq. (6)).

$R H+\mathrm{pH}_{2} \mathrm{O} \rightarrow \mathrm{CO}_{2}+n \mathrm{H}^{+}+n \mathrm{e}^{-}$
$R H+\mathrm{sH}_{2} \mathrm{O} \rightarrow I+\mathrm{mH}^{+}+m \mathrm{e}^{-}$
Let us consider here, for the sake of simplicity, a process that involves the oxidation of the organic at the anode to stable products without formation of appreciable concentrations of intermediates. This condition is, for example, usually verified at BDD anodes when the process is performed under mass transfer kinetic control. In this case, the oxidation often evolves towards the formation of carbon dioxide without formation of appreciable concentrations of intermediates [30]. Some expressions will be however generalized to the case of the presence of more organics in solution. In the next future a more complete extension of the model to the general case of pollutants forming reactive intermediates at significant concentrations in the bulk will be presented by the authors.

The following assumptions will be also made here for the sake of simplicity:

- Oxidation of the organic takes place only by anodic reactions (e.g., no homogeneous oxidation processes are considered).

- Amperostatic electrolyses are considered since the galvanostatic mode is general preferred from an applicative point of view. An uniform current density in the reactor is considered for simplicity.

- Oxidation of organics in the range of potential of oxygen evolution is considered. Thus, oxidation of organic pollutants is usually performed in these conditions to avoid the fouling of the electrodes [33].

- The only competitive process to the oxidation of $R H$ is assumed to be the oxidation of the solvent. Furthermore, we will assume that the chemi-adsorption of $R H$ and its oxidation products is negligible or that it does not affect significantly the water and organics oxidation rates.

In order to develop a theoretical model for the anodic oxidation of organics in micro reactors, the kinetic of the oxidation reaction at the electrode and the mass transfer of the organic to the electrode surface have to be considered and modelled.

\subsubsection{Mass transfer of the organic towards the anodic surface}

The geometry of the micro device is reported in Fig. 1. A parallel plate micro reactor is considered where $h$ is the height of the channel (which coincides with the inter electrodic gap), $W$ and $L$ the width and the length of the channel (and of the electrodes), respectively. Electrolyte solution flows through the reactor in the $x$-direction with an average velocity $u_{a v}$. We assume that electrodes are both very wide (e.g., $\mathrm{W} / h \gg 1$ ), so that the formulation of the problem can be approximated to a two-dimension one, and very long (e.g., $\mathrm{L} / h \gg 1)$.

Usually, the flux of the organic at the electrode $J$ as a function of $x$ is expressed by the following equation:

$$
\begin{aligned}
J & =-D\left(\frac{\partial[R H]}{\partial y}\right)_{y=0, x}=k_{m}\left([\overline{R H}]_{x}-[R H]_{y=0, x}\right) \\
& =-S h \frac{D\left([\overline{R H}]_{x}-[R H]_{y=0, x}\right)}{2 h}
\end{aligned}
$$

where $[\overline{R H}]_{X}$ is the average concentration of the organic for a given value of $x, k_{m}$ is the mass transfer coefficient and $S h=2 k_{m} h / D$ the Sherwood number. It is important to observe that the value of $S h$ 


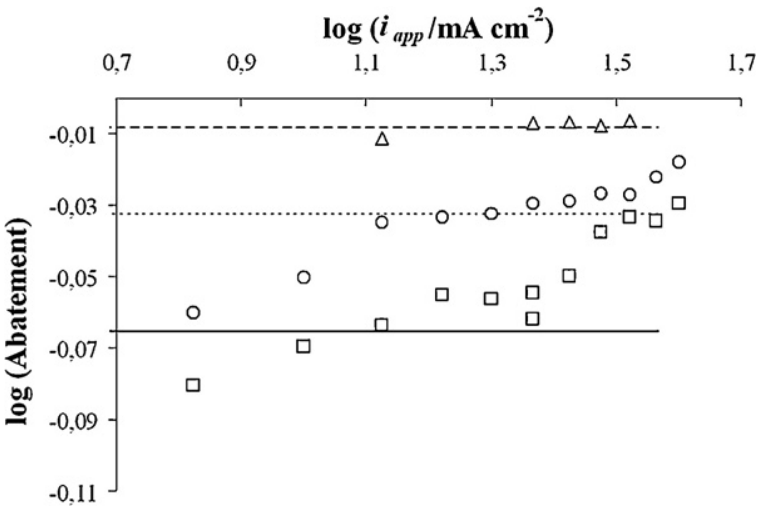

Fig. 2. Plot of the logarithm of the formic acid abatement vs. the logarithm of the current density $i$ at various flow rates: $0.2(\triangle), 0.3(\bigcirc)$ or $0.4(\square) \mathrm{ml} \mathrm{min}^{-1}$. $c^{0}=5 \mathrm{mmol} \mathrm{dm}^{-3}$. Anode: BDD, cathode: nickel, spacer nominal thickness $h: 50 \mu \mathrm{m}$. System solvent supporting electrolyte (SSE): water, $\mathrm{H}_{2} \mathrm{SO}_{4}(\mathrm{pH} 2)$. Theoretical curves $(-)$ are the predictions from Eq. (16), which derives from Eq. (7) with parameters reported in Table 1 .

depends strongly on several factors. In the absence of bubble gas evolution, the $S h$ number depends on the geometry of the channel, the ratio between the length of the entrance zone for the concentration profile and the total length of the reactor and the reaction kinetics at the reactor wall [34-39]. In particular, by neglecting the entrance zones, $S h$ is expected to assume the limiting values of 5.384 and 4.86 for oxidation reaction control and mass transfer control, respectively [34,39].

If bubble gases are formed at the electrodes, mass transfer in macrocells is likely to be controlled by two effective mechanisms: single-phase mass transfer and bubble-induced microconvection in the vicinity of adhering gas bubbles [41,42]. Furthermore the gas evolution can result in a decrease of the effective surface area [41]. Please, consider that, according to the literature, in macro cells, single-phase mass transfer is not only active in the current density region without bubble formation. Thus, in an extended region of current density, up to about $100-1000 \mathrm{~A} / \mathrm{m}^{2}$, the stirring action of gas bubbles is not strong enough to modify the mass transfer mechanism [42]. In micro reactors the presence of gas evolution can affect drastically also the flow pattern. According to the literature four basic flow patterns can be considered: bubble, slug, churned and dispersed-annular [43,44]. When gas-liquid mixtures flow upward in a vertical channel, at low superficial liquid and gas velocities (as in most of our experiments), the gas phase should be approximately uniformly distributed in the form of discrete bubbles in a continuous liquid phase [44]. Kristal et al. studied the gas evolution in micro electrochemical reactors [45]. For low current densities and high flow rate, the bubble distribution was prevalent and the current density distribution was not affected appreciably by the gas evolution. To evaluate the effect of gas evolution on the mass transfer coefficient, we have performed some preliminary experiments in the presence of formic acid at various flow rates by changing dramatically the current density in the range $3-40 \mathrm{~mA} \mathrm{~cm}^{-2}$. Experimental results are reported in Fig. 2. The plot formic acid abatement vs. current density $i_{\text {app }}$ can be divided in three parts: (i) for the lower values of the current density, the abatement of the acid increased with $i_{\text {app }}$ since the process takes place under oxidation kinetic control or under a mixed kinetic regime; (ii) in an intermediate region (current densities between about 12 and $23 \mathrm{~mA} \mathrm{~cm}^{-2}$ ), the abatement was substantially constant with $i$ as a result of mass transfer limitations from one side and a small effect of bubble gas evolution on the overall mass transfer coefficient on the other side; (iii) for higher values of the current density, the abatement slightly increased again with the current densities, thus indicating that, at these values of the current density, the bubble gas evolution changes the mass transfer mechanism resulting in higher values of the overall mass transfer coefficient. Please, consider that the second and the third part were not distinguishable at the lower adopted values of current density since very high abatements were in this case always observed.

Please consider that experiments reported in this work were usually performed at rather low values of current densities $<23 \mathrm{~mA} \mathrm{~cm}^{-2}$. As a result of it, the effect of gas evolution of mass transport was here neglected for the sake of simplicity. Thus, since the estimation of the Sh number is relevant for our objectives when the kinetics of the electrodic process is totally o partially controlled by the mass transfer of the substrate to the electrode surface, a value of 4.86 was used. Interestingly, it is possible to observe that theoretical previsions for a process under mass transfer control based on Eq. (7) and on value of Sh of 4.86 are in good agreement with experimental data at least for the intermediate region (Fig. 2). Please consider anyway that according to Fig. 2, the theoretical model may underestimate the abatement of formic acid for high values of the current density if this value of $S h$ is used. Thus, if very high values of the current density are used, the Sh number may be determined as a fitting parameter. A focused study on the effect of bubble gas evolution at high current densities will be carried out soon by the authors.

\subsubsection{Kinetic of the oxidation reaction at the anodic surface}

Under the above mentioned assumptions, the local current efficiency $C E_{x}$, for a given value of $x$ (as defined in Fig. 1), should be determined by the competition between the oxidation of the organic and the evolution of the oxygen as previously proposed by the authors for electrolyses performed in macro cells. Hence, $C E_{x}$ will be given by the following expression $[31,26,46]$ :

$C E_{x}=\frac{i_{R H}}{i_{\mathrm{app}}}=\frac{i_{R H}}{i_{R H}+i_{\mathrm{O}_{2}}}=\frac{1}{1+i_{\mathrm{O}_{2}} / i_{R H}}=\frac{1}{1+[R H]^{*} /[R H]_{x}^{y=0}}$

where $i_{R H}$ and $i_{\mathrm{O}_{2}}$ are the current densities involved in the oxidation of the organic and in the oxygen evolution process, respectively, $i_{\text {app }}$ is the applied current density, $[R H]_{x}^{y=0}$ is the concentration of the organic $R H$ at the anodic surface for a given value of $x$ and the term $[R H]^{*}$ is the value of $[R H]_{x}^{y=0}$ which gives a current density for the $R H$ oxidation equal to the current density involved for the oxygen evolution reaction, e.g. the value of $[R H]_{x}^{y=0}$ that gives a current efficiency $C E_{x}$ of $50 \%$ [26].

\subsubsection{Theoretical prediction of conversion and current efficiency}

Let us consider that under pseudo-steady state conditions, during an electrolysis carried out with amperostatic alimentation the following expression should apply for any value of $x$ :

$\left(k_{m}[\overline{R H}]_{x-}[R H]_{y=0, x}\right)=\frac{i_{\text {app }} C E_{x}}{n F}$

Hence, by combination of Eqs. (8) and (9) and elimination of the term $[R H]_{y=0, x}$, one can obtain the expression for the $C E_{x}$ during an amperostatic electrolysis [24,26,30]:

$$
C E_{X}=\frac{1}{1+2[R H]^{*} /\left([R H]^{\prime}+\left([R H]^{\prime 2}+4[R H]^{*}[\overline{R H}]_{X}\right)^{0.5}\right)}
$$

where $[R H]^{\prime}=[\overline{R H}]_{x}-[R H]^{*}-c^{*}$ and $c^{*}=i_{\text {app }} /\left(n F k_{m}\right)$ is the concentration of $R H$ that gives rise to a limiting current density $i_{\text {lim }}=n F k_{\mathrm{m}}[\overline{R H}]_{x}$ equal to the applied current density $i_{\text {app }}$.

In particular, in the limiting cases of an organic concentration, respectively, strongly higher and strongly lower than $c^{*}$ the equations reported in Table 2 can be easily derived.

If different organic molecules are present in the solution, by assuming in a first approximation approach that $C E^{\mathrm{OC}}$ is $100 \%$ for all 
Table 2

Theoretical expressions for $C E$ and $X$.

\begin{tabular}{|c|c|c|c|c|c|}
\hline Rate determining step & $C E$ & & \multicolumn{3}{|l|}{$X$} \\
\hline \multirow{2}{*}{$\begin{array}{l}\text { Oxidation reaction } \\
i_{\text {lim }} \gg i_{\text {app }} C E^{\mathrm{OC}} \\
\text { (i.e., if }[\overline{R H}]_{x} \gg c^{*}>c^{*} C E^{O C} \text { ) } \\
\text { for any value of } x\end{array}$} & $C E_{x}=\frac{1}{1+[R H]^{*} /[\overline{R H}]_{X}}$ & (11) & \multicolumn{3}{|c|}{$\begin{array}{l}X \text { is obtained by numerical combination of } \\
\text { Eqs. (11) and (12) }\end{array}$} \\
\hline & $\begin{array}{l}\text { if }[\overline{R H}]_{x} \gg[R H]^{*} \text { for any value of } x, \\
\mathrm{CE} \rightarrow 1\end{array}$ & (13) & \multicolumn{3}{|c|}{$\begin{array}{l}\text { if }[\overline{R H}]_{X} \gg[R H]^{*} \text { for any value of } x \\
X=\frac{i_{\text {app }} A}{n F c^{0} \Phi_{v}}\end{array}$} \\
\hline $\begin{array}{l}\text { Mass transfer control } \\
\qquad i_{\text {lim }} \ll i_{\text {app }} C E^{O C} \text { (i.e., if } c^{0} \ll c^{*} C E^{O C} \text { ) }\end{array}$ & $C E=\frac{n F c^{0} \Phi_{V} X}{i_{\mathrm{app}} A}$ & $(15)$ & $X=1-\exp (-$ & $\left.\operatorname{Sh} \frac{D A}{2 h \Phi_{V}}\right)$ & $(16)$ \\
\hline $\begin{array}{l}\text { Mixed kinetic regime } \\
\quad\left(“ \boldsymbol{C E}^{\mathbf{O C}}=\mathbf{1 0 0 \%} \text { ") }\right.\end{array}$ & $C E=\frac{n F c^{0} \Phi_{V} X}{i_{\mathrm{app}} A}$ & (17) & $X=1-\frac{c^{*}}{c^{0}} \exp$ & {$\left[-S h \frac{D A}{2 h V}\left(t-t^{*}\right)\right]$} & (18) \\
\hline “[RH $]^{*}=$ constant” & $C E_{x}=\frac{1}{1+2[R H]^{*} /\left([R H]^{\prime}+\left([R H]^{\prime 2}+4[R H]^{*}[\overline{R H}]_{x}\right)^{0.5}\right)}$ & $(10)$ & \multicolumn{3}{|c|}{$\begin{array}{l}X \text { is obtained by numerical combination of } \\
\text { Eqs. (10) and (12) }\end{array}$} \\
\hline
\end{tabular}

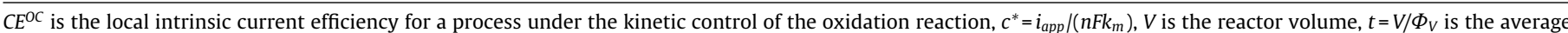

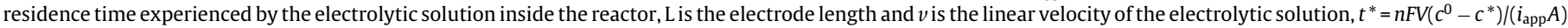
is the time necessary to decrease the concentration of the organic in the reactor to the value $c^{*}$ by an anodic process with $C E=1$.

these substances, for a process controlled by the kinetics of the oxidation reaction (e.g., for $\operatorname{COD} \gg c^{*}$ for any value of $x$ ), the abatement of $\operatorname{COD}\left(X_{\mathrm{COD}}\right)$ can be given by the following equation:

$X_{\mathrm{COD}}=\frac{i_{\mathrm{app}} A}{n F C O D^{0} \Phi_{v}}$

where $\operatorname{COD}^{0}$ is the initial chemical oxygen demand computed on a molar basis.

On the other hand, by considering an average value of the diffusion coefficient $D_{a v}, C E$ and $X_{\mathrm{COD}}$ for a process under mass transfer control (e.g. for $C O D \ll \mathrm{c}^{*} C E_{\mathrm{av}}^{\mathrm{OC}}$, where $C E_{\mathrm{av}}^{\mathrm{OC}}$ is the average $C E^{\mathrm{OC}}$ ) can be given by the following equations:

$C E=\frac{n F\left(\mathrm{COD}^{0}\right) \Phi_{V} X_{\mathrm{COD}}}{i_{\mathrm{app}} A}$

$X_{\mathrm{COD}}=1-\exp \left(-\operatorname{Sh} \frac{D_{a v} A}{2 h V} t\right)=1-\exp \left(-\operatorname{Sh} \frac{D_{a v} A}{2 h \Phi_{V}}\right)$

Let now us discuss the case of a process whose rate determining step changes across the electrode length ranging from anodic oxidation reaction control in the first zone to mass transfer control in the last part with a mixed regime between them. Two different approaches will be here used to model the process in this case.

1. " $\mathbf{C} \boldsymbol{E}^{\mathrm{OC}}=\mathbf{1 0 0 \%}$ ". Let us first consider a simplified approach based on a model proposed by Comninellis et al. [29] for the electrochemical oxidation of organics at BDD in macro reactors. The key assumption is that the oxidation of organics at BDD at high anodic potentials, close to oxygen evolution, is a very fast reaction controlled by mass transport to the anode. Particularly, it is assumed that, if $[\overline{R H}]_{x}>c^{*}$, the current efficiency for the abatement of the organic is $100 \%$ while for $[\overline{R H}]_{x}<c^{*}$ the process is under mass transfer control and the current efficiency is given by the ratio between the limiting current density $i_{\lim }=n F k_{\mathrm{m}}[\overline{R H}]_{X}$ and the applied current density $i_{\text {app. }}$. As a consequence $C E$ and $X$ for an initial (inlet) and final (outlet) concentration of the organic higher and lower than $c^{*}$, respectively, are given by Eqs. (17) and (18) reported in Table 2.

If more organics are present in the solution Eqs. (17b) and (18b) can be used (where $t_{C O D}^{*}=\left(n F V\left(C O D^{0}-c^{*}\right) /\left(i_{\text {app }} A\right)\right)$.

$C E=\frac{n F\left(C O D^{0}\right) \Phi_{V} X}{i_{\mathrm{app}} A}$

$$
X_{\mathrm{COD}}=1-\frac{c^{*}}{\mathrm{COD}^{0}} \exp \left[-\operatorname{Sh} \frac{D A}{2 h V}\left(t-t_{\mathrm{COD}}^{*}\right)\right]
$$

2. " $[\boldsymbol{R H}]^{*}=$ constant". Let us now consider another approximated approach based on the assumption that $[R H]^{*}$ can be considered as a constant for a couple electrodic material - organic pollutant for a fixed value of the temperature. Please, consider that this hypothesis is more reliable in the case of a direct anodic oxidation process (if the transfer coefficients $\alpha$ of the oxidation of water and of organic assume similar values) or for an oxidation mediated by chemisorbed hydroxyl radicals. Differently, for an oxidation reaction mediated by physical adsorbed or free hydroxyl radicals, $[R H]^{*}$ is likely to change with the working potential and then with the applied current density so that in this case an average value of $[R H]^{*}$ can be considered. Quite interestingly, if $[R H]^{*}$ is assumed to be constant, the current efficiency for any value of $x$ can be readily computed by Eq. (10), so that the abatement $X$ can be easily numerically obtained by combining Eqs. (10) and (12) as a function of the geometric characteristics of the micro reactor, the $\Phi_{V}$ and $[R H]^{*}$.

Please, consider that all the equations above presented can be readily used for the prediction of the abatement and the current efficiency since all the involved parameters can be easily determined or estimated a priori. Thus the mass transfer coefficient can be readily obtained from equation $k_{m}=S h D /(2 h)$. The diffusion coefficient $D$ can be often found in the literature, computed by electroanalytical experiments or by the Wilke-Chang expression. The value of $[R H]^{*}$ can be estimated by one electrolysis performed in conventional macro reactors under kinetic control of the oxidation reaction $[26,31]$ while a constant value can be used for the $S h$ number (see Section 3.1.1) if entry zone and gas evolution effects can be neglected. On the other hand, for high values of the current density, the $S h$ number has to be selected as a fitting parameter to take in account for gas evolution effect on mass transport phenomena.

\subsection{Experimental results. Effect of operative parameters on the abatement and the current efficiency}

The effect of some operative parameters, such as the applied current density $i_{\mathrm{app}}$, the flow rate $\Phi_{V}$, the initial organic concentration $c^{0}$ and the distance between the electrodes $h$, on the anodic oxidation of organics in water was studied to individuate the optimal operative conditions of the process. Electrolyses were performed in a continuous mode in the micro reactor described in Table 1 

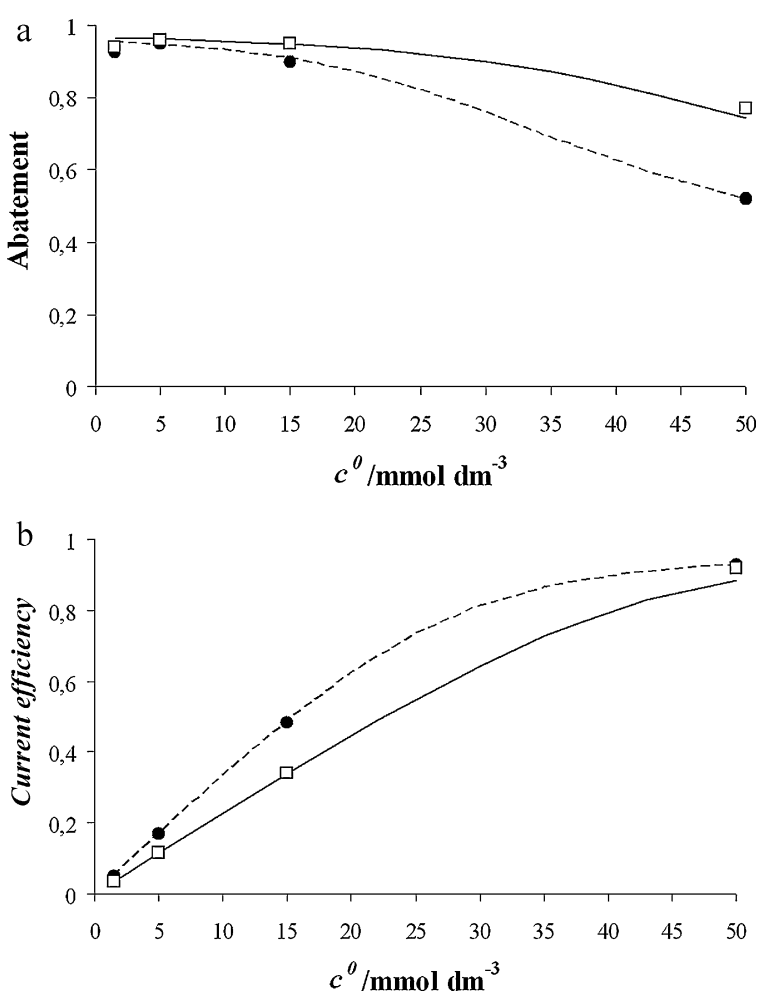

Fig. 3. Formic acid abatement $X$ (Fig. 3a) and current efficiency $C E$ (Fig. 3b) vs. inlet concentration $c^{0}$. Anode: BDD, cathode: nickel. Flow rate $\Phi_{V}: 0.2 \mathrm{ml} \mathrm{min}^{-1}$. Applied current density: $6.7(\bullet)$ or $10 \mathrm{~mA} \mathrm{~cm}^{-2}(\square)$. Spacer nominal thickness $h: 50 \mu \mathrm{m}$. System solvent supporting electrolyte (SSE): water, $\mathrm{H}_{2} \mathrm{SO}_{4}(\mathrm{pH} 2)$. Theoretical curves are the predictions from Eqs. (10) and (12) for $i_{\text {app }}=6.7(--)$ and $10 \mathrm{~mA} \mathrm{~cm}^{-2}$ (-) with parameters reported in Table 1.

by a single passage of the electrolytic solution inside the cell. In few cases two passages inside the cell were operated. Most of the experiments were performed with a nominal distance between electrodes of $50 \mu \mathrm{m}$. In some cases micro devices with a distance of $75 \mu \mathrm{m}$ were also used to study the effect of $h$ on the performances of the process.

\subsubsection{Effect of the initial concentration $c^{0}$}

To evaluate the role of the initial (inlet) acid concentration $c^{0}$ on the performances of the process, some amperostatic experiments were performed with different values of $c^{0}(1.5,5,15$ and $50 \mathrm{mmol} \mathrm{dm}^{-3}$ ) at two different $i_{\text {app }}\left(6.7\right.$ and $\left.10 \mathrm{~mA} \mathrm{~cm}^{-2}\right)$, a $\Phi_{V}$ of $0.2 \mathrm{ml} \mathrm{min}^{-1}$ and a nominal distance between the electrodes $h$ of $50 \mu \mathrm{m}$.

For low values of the initial concentration $\left(c^{0} \leq 5 \mathrm{mmol} \mathrm{dm}^{-3}\right)$, the abatement of formic acid was very high $(X>95 \%)$ and did not depend appreciably on the values of $c^{0}$ and $i_{\text {app }}$ (Fig. 3a) while the current efficiency increased linearly with $c^{0}$ and decreased with $i_{\text {app }}$ (Fig. 3b). To explain this behaviour, one can observe that, when the experiments were performed with the two lowest adopted substrate concentrations ( 1.5 and $5 \mathrm{mmol} \mathrm{dm}^{-3}$ ), the process was kinetically controlled by the mass transfer of the organic pollutant to the anodic surface $\left(c^{0}\right.$ drastically lower than $c^{*}$, which is 7.1 and $10.6 \mathrm{mmol} \mathrm{dm}^{-3}$ for $i_{\text {app }}$ of 6.7 and $10.0 \mathrm{~mA} \mathrm{~cm}^{-2}$, respectively). Thus, as shown in Section 3.1.3, for a process under mass transfer control, the abatement $X$ is expected to be independent on $c^{0}$ or $1 / i_{\text {app }}$ and the $C E$ to increase linearly with both parameters (see Eqs. (15) and (16)).

Conversely at $c^{0}=50 \mathrm{mmol} \mathrm{dm}{ }^{-3}$, when a reaction oxidation control is expected for a large part of the experiment $\left(c^{0} \gg c^{*}\right)$, a significant decrease of the abatement $X$ and conversely an increase of the current efficiency was observed with respect to the
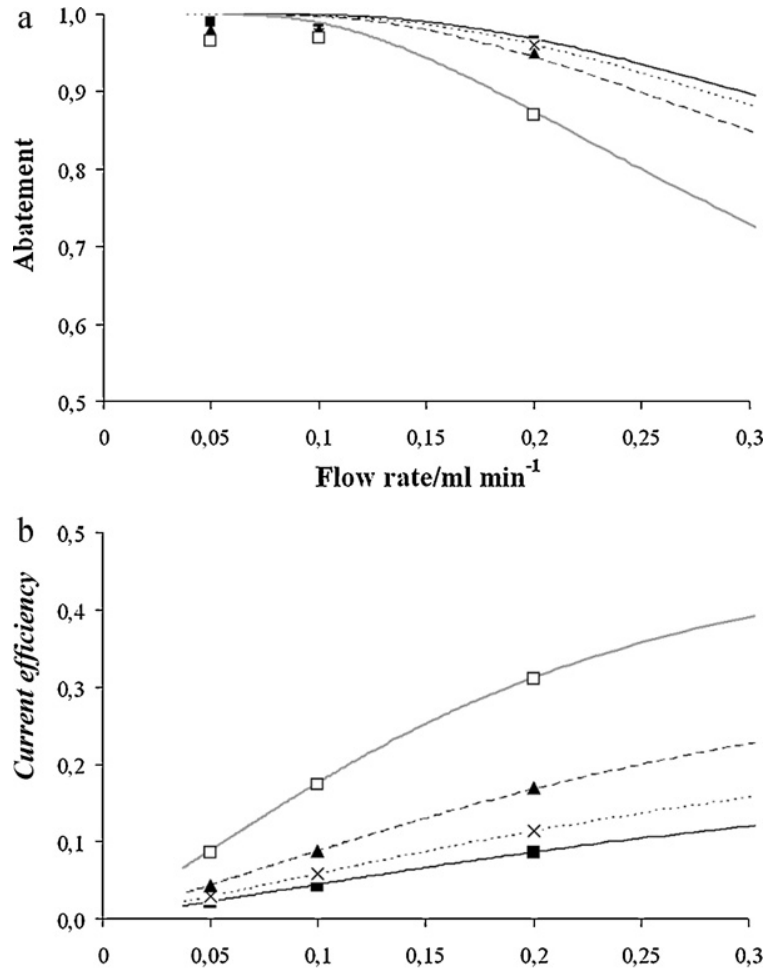

Flow rate $/ \mathrm{ml} \mathrm{min}^{-1}$

Fig. 4. Formic acid abatement $X$ (Fig. 4a) and current efficiency $C E$ (Fig. 4b) vs. flow rate at various current densities ( $3(\square), 7(\boldsymbol{\Lambda}), 10(\times), 13(\boldsymbol{\square}) \mathrm{mA} \mathrm{cm}^{-2}$ ). Anode: BDD cathode: nickel, spacer nominal thickness $h: 50 \mu \mathrm{m}$. Initial concentration of formic acid $c^{0} 5 \mathrm{mmol} \mathrm{dm}^{-3}$. System solvent supporting electrolyte (SSE): water, $\mathrm{H}_{2} \mathrm{SO}_{4}$ (pH 2). Theoretical curves (-) are the predictions from Eqs. (10) and (12) with parameters reported in Table 1.

experiments performed with lower $c^{0}$. In this case, as predicted by theoretical considerations resumed by Eqs. (11)-(14), $X$ was strongly dependent on $i_{\text {app }}$ and the $C E$ was close to 1 .

\subsubsection{Effect of the flow rate and of the current density}

The effect of flow rate $\Phi_{V}$ and applied current density $i_{\text {app }}$ was investigated by operating a series of electrolyses with two initial values of $c^{0}$ (5 and $15 \mathrm{mmol} \mathrm{dm}{ }^{-3}$ ) with $h=50 \mu \mathrm{m}$ changing $\Phi_{V}$ from 0.05 to $0.3 \mathrm{ml} \mathrm{min}^{-1}$ and $i_{\text {app }}$ from 2 to $23 \mathrm{~mA} \mathrm{~cm}^{-2}$.

Fig. 4 reports the results of the experiments performed with $c^{0}=5 \mathrm{mmol} \mathrm{dm}^{-3}$. In these conditions a very high abatement ranging between 97 and $99 \%$ was obtained with the exception of the experiment performed at the lowest $i_{\text {app }}\left(3.3 \mathrm{mAcm}^{-2}\right)$ and the highest adopted $\Phi_{V}\left(0.2 \mathrm{ml} \mathrm{min}^{-1}\right)$ when $X$ was about $87 \%$. With the exception of this electrolysis, a very slight effect of $i_{\text {app }}$ and $\Phi_{V}$ on $X$ was observed. The low effect of $i_{\text {app }}$ is due to the fact that under adopted operative conditions, the process is close to be under a pure mass transfer control $\left(c^{0}<c^{*}\right)$ for all the performed experiments with the exception of that operated at $3.3 \mathrm{mAcm}^{-2}$ $\left(c^{*}=3.5 \mathrm{mmol} \mathrm{dm}^{-3}\right)$. The low effect of $\Phi_{V}$ could be explained because the residence time is always sufficiently high to convert almost all the introduced moles of organic for a process under mass transfer kinetic control. These low effects of $\Phi_{V}$ and $i_{\text {app }}$ on the abatement had nevertheless a significant impact on the current efficiency, since they affect the charge passed per unit of volume of electrolytic solution for unit of time. Thus, higher current efficiencies were observed upon increasing the $\Phi_{V}$ and decreasing $i_{\text {app }}$ (Fig. 4b).

As shown in Fig. 5, a quite different picture was observed when the organic concentration was increased to $c^{0}=15 \mathrm{mmol} \mathrm{dm}^{-3}$. For a $\Phi_{V}$ up to $0.1 \mathrm{ml} \mathrm{min}^{-1}$, very high abatements among 98 and $99 \%$ 

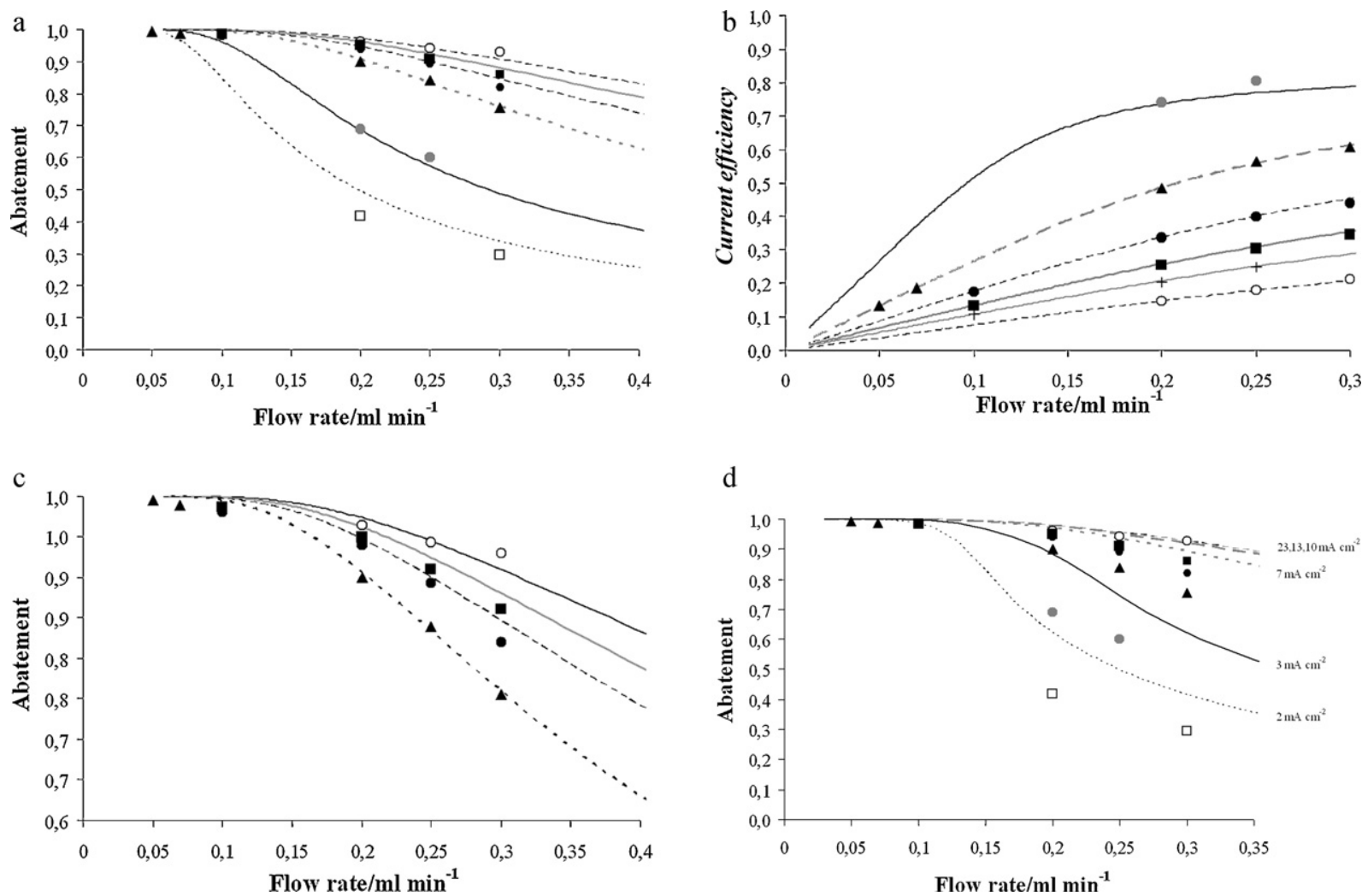

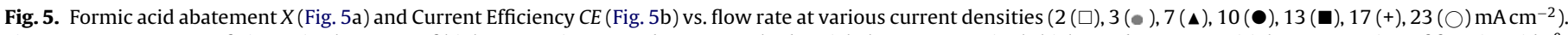

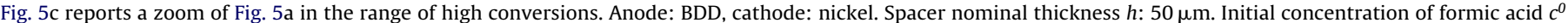

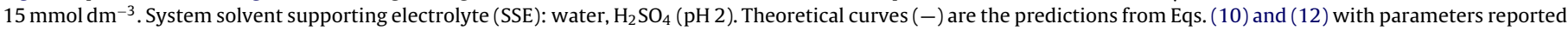
in Table 1. Fig. 5d reports a comparison between abatement of formic acid $X$ for experiments reported in Fig. $5 \mathrm{a}$ and theoretical predictions based on Eq. (18).

were observed for any value of adopted $i_{\text {app }}$ after a single passage of the solution through the cell (Fig. 5a and c). For higher values of the $\Phi_{V}$, conversions changed drastically with $i_{\text {app }}$. Thus, as an example, for $\Phi_{V}=0.2 \mathrm{ml} \mathrm{min}^{-1}$ an abatement slightly higher than 40 and $95 \%$ was obtained by operating at 2 and $23 \mathrm{~mA} \mathrm{~cm}^{-2}$, respectively. The effect of $i_{\text {app }}$ at high $\Phi_{V}$ is due to the fact that for this value of $c^{0}$ the process enters in a mixed kinetic regime. At fixed values of $i_{\mathrm{app}}$, higher $\Phi_{V}$ led to a decrease of the abatement of formic acid as a result of the lower residence time. This decrease was very low for high current density and more relevant for low $i_{\text {app. }}$.

Also in this case, $\Phi_{V}$ and $i_{\text {app }}$ had a significant impact on the current efficiency. Thus, drastic higher current efficiencies were observed upon increasing $\Phi_{V}$ and decreasing $i_{\text {app }}$ (Fig. 5b). As an example, for $\Phi_{V}=0.2 \mathrm{ml} \mathrm{min}^{-1}, C E$ changed from about $70-20 \%$ when $i_{\text {app }}$ passed from 3 to $17 \mathrm{~mA} \mathrm{~cm}^{-2}$.

\subsubsection{Effect of the distance between the electrodes and of the anode surface}

The performances of the electrochemical treatment of waste waters contaminated by organic pollutants, in terms of abatements and current efficiencies, are expected to be dramatically affected in micro reactors by the distance between the electrodes, i.e. the height of the reactor, $h$ [18]. To study the effect of this crucial parameter, some experiments were repeated with an initial concentration of FA of $15 \mathrm{mmol} \mathrm{dm}^{-3}$ and three spacers of $25 \mu \mathrm{m}$ for a total value of $h$ of about $75 \mu \mathrm{m}$. As shown in Fig. 6, an increase of $h$ from 50 to $75 \mu \mathrm{m}$ resulted in lower abatements and current efficiencies at both 7 and $23 \mathrm{~mA} \mathrm{~cm}^{-2}$. As an example at $23 \mathrm{~mA} \mathrm{~cm}^{-2}$, for a $\Phi_{V}$ of $0.3 \mathrm{ml} \mathrm{min}^{-1}, X$ decreased from 93 to $80 \%$, when $h$ changed from 50 to $75 \mu \mathrm{m}$. When similar experiments were repeated at $7 \mathrm{mAcm}^{-2}$, $X$ decreased from 75 to about $60 \%$. The strong effect of $h$ on $X$ results from the fact that under adopted operative conditions the process
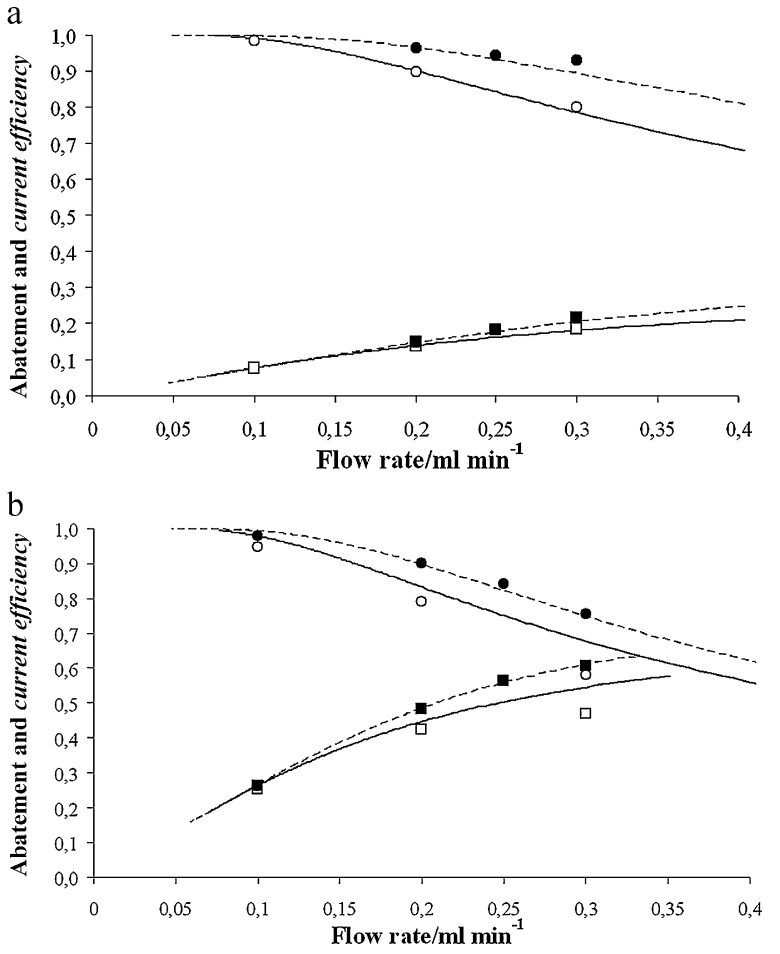

Fig. 6. Abatement $X$ (for $h=50(\bullet)$ and $75 \mu \mathrm{m}(\bigcirc)$ ) and current efficiency $C E$ (for $h=50(\square)$ and $75 \mu \mathrm{m}(\square)$ ) vs. flow rate at 23 (Fig. 6a) and $7 \mathrm{~mA} \mathrm{~cm}^{-2}$ (Fig. 6b). Anode: BDD, cathode: nickel. Initial concentration of formic acid $c^{0}: 15 \mathrm{mmol} \mathrm{dm}^{-3}$. System solvent supporting electrolyte (SSE): water, $\mathrm{H}_{2} \mathrm{SO}_{4}(\mathrm{pH} 2)$. Theoretical curves are the predictions from Eqs. (10) and (12) for $h=50(--)$ and $75 \mu \mathrm{m}(-)$ with parameters reported in Table 1. 


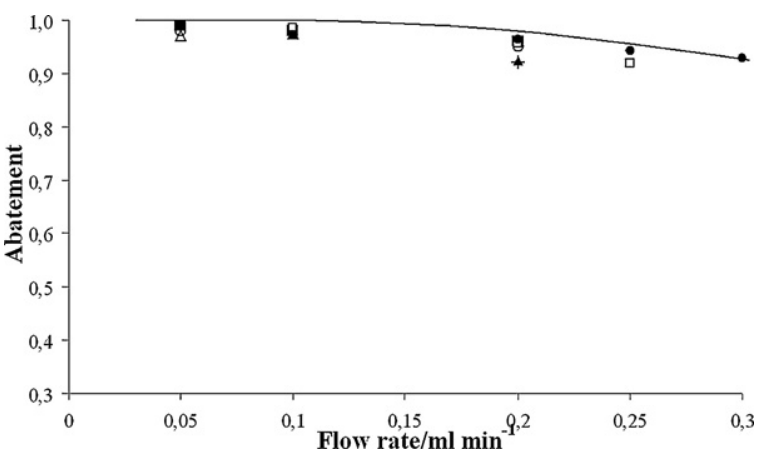

Fig. 7. Formic acid abatement $X$ vs. flow rate for experimental conditions reported in Table 3, at various current densities and initial concentrations of formic acid: $3 \mathrm{~mA}$ $\mathrm{cm}^{-2}$ and $1.5 \mathrm{mmol} \mathrm{dm}^{-3}(+), 7 \mathrm{mAcm}^{-2}$ and $1.5 \mathrm{mmol} \mathrm{dm}^{-3}(\Delta), 7 \mathrm{mAcm}^{-2}$ and $5 \mathrm{mmol} \mathrm{dm}^{-3}$. $(\bigcirc), 10 \mathrm{~mA} \mathrm{~cm}^{-2}$ and $5 \mathrm{mmol} \mathrm{dm}^{-3}(\triangle), 13 \mathrm{~mA} \mathrm{~cm}^{-2}$ and $5 \mathrm{mmol} \mathrm{dm}^{-3}$ $(\square), 17 \mathrm{~mA} \mathrm{~cm}^{-2}$ and $15 \mathrm{mmol} \mathrm{dm}^{-3}(\square), 23 \mathrm{~mA} \mathrm{~cm}^{-2}$ and $15 \mathrm{mmol} \mathrm{dm}^{-3}(\bullet)$. Anode: BDD, cathode: nickel. Spacer nominal thickness $h$ : $50 \mu \mathrm{m}$. System solvent supporting electrolyte (SSE): water, $\mathrm{H}_{2} \mathrm{SO}_{4}(\mathrm{pH} 2)$. Other operative conditions listed in Table 3. Theoretical curves (-) are the predictions from Eq. (16) with parameters from Table 1.

is under mass transfer control or under a mixed kinetic regime. Thus, for a process kinetically governed by the mass transfer, the conversion depends exponentially on $1 / h$ (see Eq. (16)). Please note that also the electrode surface area $A$ is expected to affect strongly the performances of the process. In particular, $X$ should depend exponentially and linearly on $A$ for a process under mass transfer (Eq. (16)) and oxidation reaction control (Eq. (14)), respectively. The effect of $A$ was here studied by comparing some electrolyses performed with a single and a double passage inside the cell that is equivalent to the utilization of a double value of the surface $A$. In particular, at $c^{0}=15 \mathrm{mmol} \mathrm{dm}^{-3}, i_{\text {app }}=7 \mathrm{mAcm}^{-2}$ and $\Phi_{V}=0.2 \mathrm{ml} \mathrm{min}^{-1}, X$ was $90 \%$ and $99 \%$ after one and two passages inside the cell, respectively, as a result of the higher surface area encountered by the acid.

\subsection{Comparison between theoretical predictions and experimental results}

As previously discussed in Section 3.2, a good qualitative agreement between theoretical predictions and experimental results was observed. In the following we wish to evaluate if also a quantitative agreement arises. Let us focus our attention first on a process kinetically controlled by mass transfer. This was realized by operating several electrolyses with $c^{0}<c^{*}$ at various operative conditions summarised in Table 3. Please, note that in the case of a process under mass transfer control, according to theoretical predictions and in detail to Eq. (16), the abatement is not expected to depend

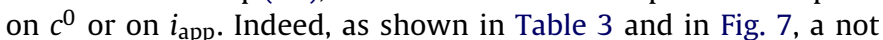
appreciable effect of $i_{\text {app }}$ on $X$ was observed (see in Table 3, entries 1 and 2, 4 and 5, 6 and 7,8 and 9). Similar values of the conversion were also achieved by performing the electrolyses at the same $\Phi_{V}$ but with an initial concentration of 5 or $15 \mathrm{mmol} \mathrm{dm}^{-3}$ (see Fig. 7 and Table 3, entries 7-11). On the other hand, the experiments performed with $c^{0}=1.5 \mathrm{mmol} \mathrm{dm}{ }^{-3}$ resulted in slightly lower values of $X$ (Table 3, entries 1-3).

As shown in Fig. 7, a good quantitative agreement between theoretical predictions obtained from Eq. (16) with parameters reported in Table 1 and experimental data was observed in spite of the fact that no adjustable parameters are used. Abatements just slightly lower than theoretical predictions were observed. To tentatively explain these small differences, one can observe that the pollutant concentrations at the electrode surface can be slightly higher than zero in its initial portion, thus giving rise to lower mass transfer rate with respect to that implicitly estimated by Eq. (16).
A slightly higher difference between theoretical predictions and experimental data was observed for the electrolyses performed with the lowest values of $c^{0}\left(1.5 \mathrm{mmol} \mathrm{dm}^{-3}\right)$ and $i_{\mathrm{app}}$. However for this initial concentration, $c^{0}<[R H]^{*}$ and, as a consequence, $C E^{\mathrm{OC}}$ is expected to be significantly lower than $100 \%$. Thus, we are in the particular case of $c^{0}<c^{*}$ but not sufficiently lower than $c^{*} C E^{\mathrm{OC}}$.

The quite good agreement between experimental data and theoretical predictions shows that the mass transfer process can be well simulated by Eq. (7) by using a constant value of the Sh number in spite of the numerous approximations involved in this approach. Please, consider anyway that this approximation can be used if not too high values of the current density. Thus, at high values of $i_{\text {app }}$ the effect of bubble gas evolution on flowdynamic pattern cannot be more neglected (see Fig. 2 and Section 3.1.1). Quite interestingly, this allows an easy comparison between mass transfer rates in conventional and micro reactors. In the first case, a turbulent regime is usually involved and the mass transport process can be easily described by considering the occurrence of a linear concentration profile inside the stagnant layer. Thus, the flux of the organic at the electrode $J$ can be expressed by the following equation:

$J=-D\left(\frac{\partial C}{\partial y}\right)_{y=0}=-k_{m}\left([R H]^{b}-[R H]^{y=0}\right)=-\frac{D\left([R H]^{b}-[R H]^{y=0}\right)}{\delta}$

where $[R H]^{b}$ and $[R H]^{y=0}$ are the concentrations of the organic in the bulk of the solution (which coincides with the average organic concentration) and at the anodic surface, respectively, and $\delta$ is the thickness of the stagnant layer which depends on the fluidodynamic regime. Hence, in order to achieve a first approximation comparison between mass transfer rates in micro and macro reactors one can compare Eqs. (7) and (19), which give the flux of the organic at the electrodic surface for a micro and a macro reactor, respectively. It follows that a faster mass transfer is expected in the micro reactor only if $2 h / S h<\delta$. As a consequence, since $\delta$ presents usually values among 10 and $100 \mu \mathrm{m}$ and $S h^{\alpha}$ for parallel plate electrodes is close to 5 , a micro reactor is expected to present mass transfer kinetics comparable or faster than that achieved in conventional macro reactors only if low values of $h$ of tens of micrometers are used. On the other hand, please consider that it is possible to achieve higher Sh number by the utilization of short micro reactors with high ratio between the length of the entrance zones with respect to their total length (see Section 3.1.1) or by using "segmented" reactors (i.e., microfluidic reactors composed by numerous and short electrodes). As an example, for a length of the micro reactor of about $0.006 u_{\text {av }} h^{2} / D$, a $S h$ number close to 10 is expected according to the literature [35]. Another potentially way to increase the mass transfer rates in a micro reactor is the utilization of a coupled process that allows the simultaneous anodic and cathodic abatement of organic pollutants [40]. Thus, in this case a drastic increase of the fluxes to both electrodes is expected so that a value of $S h^{\alpha}$ close to 7.6 is expected for each electrodic process [39]. Furthermore, a possible intensification of mass transport phenomena may occur at high current density due to gas evolution effects (see Section 3.1.1).

Let us consider now a process completely controlled by the oxidation reaction. This situation arises if $c^{0}(1-X) \gg c^{*}$ (e.g. if $c^{0}>c^{*}$ and the residence time $t$ is lower than $t^{*}$ for a process with $C E^{\mathrm{OC}}$ close to 1 ). This is the case for electrolyses performed with $c^{0}=50 \mathrm{mmol} \mathrm{dm}^{-3}$ at high $\Phi_{V}$ and moderate values of $i_{\text {app }}$ (6.7 and $10.0 \mathrm{~mA} \mathrm{~cm}^{-2}$ ) to have small $c^{*}$ and residence time $t$ lower than $t^{*}$ (see Table 4). According to theoretical predictions, for a fixed value of $\Phi_{V}$ quite high values of $C E$ substantially independent on $i_{\text {app }}$ were observed (Table 4). Conversely the conversion $X$ decreased strongly by decreasing $i_{\text {app }}$ and enhancing $\phi_{V}$. 
Table 3

Experiments performed with $c^{0}<c^{*}$.

\begin{tabular}{|c|c|c|c|c|c|c|}
\hline Entry & $i_{\text {app }}\left(\mathrm{mAcm}^{-2}\right)$ & $\Phi_{V}\left(\mathrm{ml} \mathrm{min}{ }^{-1}\right)$ & $c^{0}\left(\mathrm{mmol} \mathrm{dm}^{-3}\right)$ & $c^{*}\left(\mathrm{mmol} \mathrm{dm}^{-3}\right)$ & $X(\%)$ & $C E(\%)$ \\
\hline 1 & 3.3 & 0.20 & 1.5 & 3.5 & 92 & 9.9 \\
\hline 2 & 6.7 & 0.20 & 1.5 & 7.1 & 92 & 5.0 \\
\hline 3 & 6.7 & 0.10 & 1.5 & 7.1 & 97 & 2.6 \\
\hline 4 & 10.0 & 0.05 & 5 & 10.6 & 98 & 2.9 \\
\hline 5 & 13.3 & 0.05 & 5 & 14.2 & 99 & 2.2 \\
\hline 6 & 10.0 & 0.10 & 5 & 10.6 & 98 & 5.8 \\
\hline 7 & 13.3 & 0.10 & 5 & 14.2 & 98 & 4.4 \\
\hline 8 & 10.0 & 0.20 & 5 & 10.6 & 96 & 11.4 \\
\hline 9 & 13.3 & 0.20 & 5 & 14.2 & 96 & 8.6 \\
\hline 10 & 16.7 & 0.10 & 15 & 17.7 & 99 & 10.6 \\
\hline 11 & 16.7 & 0.20 & 15 & 17.7 & 96 & 20.5 \\
\hline 12 & 16.7 & 0.25 & 15 & 17.7 & 92 & 24.7 \\
\hline
\end{tabular}

a Amperostatic electrolyses, room temperature, electrolytic solution: water, $\mathrm{H}_{2} \mathrm{SO}_{4}(\mathrm{pH} 2), h=50 \mu \mathrm{m}$.

Table 4

Experiments performed with $c^{0} \gg c^{*}$.

\begin{tabular}{|c|c|c|c|c|c|c|c|}
\hline$i_{\text {app }}\left(\mathrm{mAcm}^{-2}\right)$ & $\Phi_{V}\left(\mathrm{ml} \mathrm{min}{ }^{-1}\right)$ & $t(\mathrm{~s})$ & $t^{*}(\mathrm{~s})$ & $c^{0}\left(\mathrm{mmol} \mathrm{dm}^{-3}\right)$ & $c^{*}\left(\mathrm{mmol} \mathrm{dm}^{-3}\right)$ & $X(\%)$ & $C E(\%)$ \\
\hline 6.7 & 0.13 & 5.4 & 6.2 & 50 & 7.1 & 78 & 89 \\
\hline 6.7 & 0.20 & 3.5 & 6.2 & 50 & 7.1 & 54 & 95 \\
\hline 6.7 & 0.25 & 2.8 & 6.2 & 50 & 7.1 & 40 & 88 \\
\hline 6.7 & 0.30 & 2.3 & 6.2 & 50 & 7.1 & 33 & 87 \\
\hline 10.0 & 0.20 & 3.5 & 3.8 & 50 & 10.6 & 77 & 90 \\
\hline 10.0 & 0.25 & 2.8 & 3.8 & 50 & 10.6 & 58 & 85 \\
\hline 10.0 & 0.30 & 2.3 & 3.8 & 50 & 10.6 & 50 & 88 \\
\hline
\end{tabular}

a Amperostatic electrolyses, room temperature, electrolytic solution: water, $\mathrm{H}_{2} \mathrm{SO}_{4}(\mathrm{pH} 2), h=50 \mu \mathrm{m}$.

Under the assumption that $C E$ is close to $100 \%$ for a process under oxidation reaction control, the abatement $X$ can be easily estimated by Eq. (14). As shown in Fig. 8, theoretical predictions are quite close to the experimental points for most of experiments. It can be observed, however that Eq. (14) slightly overestimates $X$ since real current efficiencies were usually slightly lower than $100 \%$ (see Table 4). A more accurate prediction was obtained estimating the CE by Eq. (11) and the conversion $X$ by combining Eqs. (11) and (12) (see Fig. 8).

Hence, experimental results are in good agreement with theoretical predictions in the two limiting cases of processes purely controlled by oxidation reaction or mass transfer. Let us now discuss the general case of a process whose rate determining step changes across the reactor from an oxidation reaction control in the first part of it to mass transfer control in the last part with a mixed regime between them. In this case a general expression for the instantaneous current efficiency has to be adopted. As previously mentioned two different approaches can be used. In the first one (denoted here " $C E^{\mathrm{OC}}=100 \%$ "), the oxidation reaction is

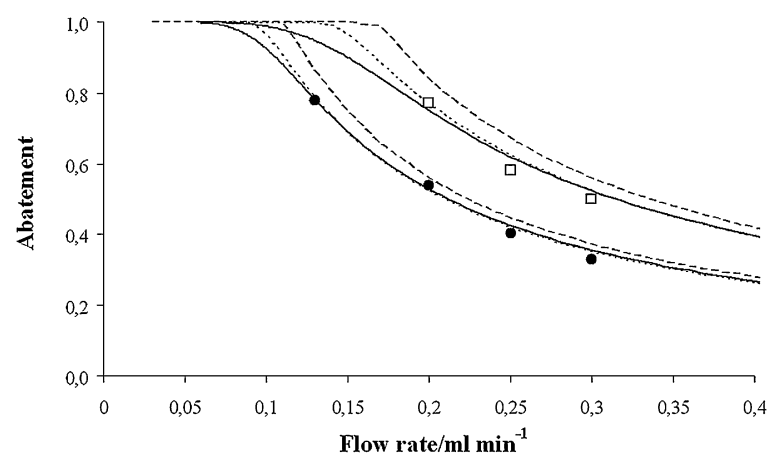

Fig. 8. Formic acid abatement $X$ vs. flow rate for experimental conditions reported in Table 4. Applied current density: $6.7(\bullet)$ or $10 \mathrm{~mA} \mathrm{~cm}^{-2}(\square)$. Anode: BDD, cathode: nickel. Spacer nominal thickness $h: 50 \mu \mathrm{m}$. System solvent supporting electrolyte (SSE): water, $\mathrm{H}_{2} \mathrm{SO}_{4}(\mathrm{pH} 2)$. Other operative conditions listed in Table 4. Theoretical curves are based on Eq. (14) (--), Eqs. (11) and (12) (....), Eqs. (10) and (12) (-) with parameters from Table 1. assumed to be very fast to be under mass transfer control. Hence, the current efficiency is $100 \%$ if $[R H]_{X}>C^{*}$ and it is given by the ratio between the limiting current and the applied current intensity for $[R H]_{X}<c^{*}$. Under these assumptions, as reported in Section 3.1.3, the abatement can be readily estimated by Eq. (18). In Fig. 5d experimental data obtained with $c^{0}=15 \mathrm{mmol} \mathrm{dm}^{-3}$ and various $\Phi_{V}$ and $i_{\text {app }}$ were compared with theoretical predictions obtained by Eq. (18). A very good agreement was observed for the highest adopted $i_{\text {app }}$, e.g. when the process was under nearly purely mass transfer control. On the other hand, for the other adopted $i_{\text {app }}$, the model overestimates experimentally determined $X$. This is probably due mainly to two reasons. First, the adopted model assumes a concentration at the electrode close to zero for any portion where $[\overline{R H}]_{x}<c^{*}$. This is certainly true for a process under a purely mass transfer control (i.e., $[\overline{R H}]_{x} \ll c^{*}$ ). Otherwise when $[\overline{R H}]_{X}$ is not sufficiently lower than $c^{*}$, the acid concentration at the electrodic surface $[R H]_{x}^{y=0}$ is likely to be different than zero. Hence, the real mass flux $k_{m}\left([R H]_{x}-[R H]_{x}^{y=0}\right)$ should be lower than its limiting value $k_{\mathrm{m}}[R H]_{x}$ considered by the model for $[R H]_{x}<c^{*}$ so that an overestimation of $C E$ is expected. Second, for $[R H]_{x}>c^{*}$, the model assumes a current efficiency of $100 \%$. Please note that this assumption is rigorously true only when $[R H]_{x} \gg[R H]^{*}$, e.g., if both $c^{0}$ and $(1-X) c^{0}$ are drastically higher than $[R H]^{*}$. If this condition is not verified, the current efficiency is expected to be lower than $100 \%$ and as a consequence the model overestimates the experimental conversions.

Let us now compare experimental data with theoretical predictions based on the assumption that $[R H]^{*}$ assumes a constant value for a fixed couple electrodic material/organic pollutant. As shown in Fig. $5 \mathrm{a}-\mathrm{c}$ for experiments performed with $c^{0}=15 \mathrm{mmol} \mathrm{dm}^{-3}$, a good agreement between experimental data and theoretical predictions based on Eqs. (10) and (12) was observed for a very wide range of flow rates and current densities in spite of the simplifications introduced in the model and that no adjustable parameters are used. Thus, a very good correlation between theoretical and experimental data with a $r_{x y}$ (Correlation parameter of Bravais and Parson) higher than 0.98 was observed. Please note by comparing Fig. 5a and d that the second approach (" $[R H]^{*}$ constant") 
leads to much more accurate predictions with respect to that of the first approach (" $C E^{\mathrm{OC}}=100 \%$ "). However, also this model showed a limited accuracy for the experiments performed with the lowest adopted $i_{\text {app }}\left(2 \mathrm{~mA} \mathrm{~cm}^{-2}\right)$. Otherwise, for these small values of $i_{\text {app }}$ the working potential is expected to be very close or lower than the potential of insurgence of the oxygen evolution so that the hypothesis of a process performed under the range of oxygen evolution is not strictly respected. As shown in Fig. 5c, abatement slightly lower than theoretical predictions were observed also for the lowest adopted $\Phi_{V}$. This could arise from a not negligible axial dispersion causing back mixing phenomena and reducing the final conversions or to the accumulation of gas bubbles on the electrodic surface, thus reducing the effective working surface.

As shown in Fig. 4, the theoretical model allowed to predict with good accuracy the effect of $\Phi_{V}$ and $i_{\text {app }}$ also when the inlet organic concentration was $5 \mathrm{mmol} \mathrm{dm}^{-3}$. Furthermore, the model predicts with a very good accuracy also the effect of $c^{0}$ (Fig. 3) and $h$ (Fig. 6) on both the abatement and the current efficiency of the process.

\section{Conclusions}

In this work we have studied the effect of various experimental conditions on the performances of the process of oxidation of aqueous solution of formic acid in micro reactors at BDD anode in micro reactors in terms of both conversion and current efficiency:

- Very high abatements were obtained by working with low distances between the electrodes $h$, sufficiently high residence times (e.g., low flow rates) and/or current densities.

- When most part of the process was under oxidation reaction kinetic control, i.e., when low current densities, low residence times and high concentrations of the organic are involved, high current efficiencies were observed which did not depend significantly on the applied current density. Conversely, the conversion $X$ was strongly dependent on both $i_{\text {app }}$ and flow rate.

- When the process was under mass transfer control, the abatement did not depend on the initial concentration of FA but on the flow rate and on the value of $h$. Current efficiency increased with $h, c^{0}$ and $1 / i_{\text {app }}$ and flow rate. For not too high values of the current intensity, $X$ did not depend on $i_{\text {app }}$. Conversely, at high values of the current intensity, $X$ changed with $i_{\text {app }}$ for its effect on the gas evolution and consequently on the flow dynamic pattern.

A simple theoretical model was proposed to describe the electrochemical oxidation of organics in micro reactor under mass transfer control, oxidation reaction control and mixed kinetic

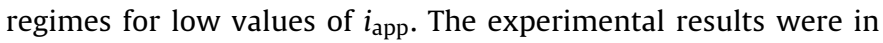
very good agreement with the previsions of the model, in spite of the fact that no adjustable parameter was used, thus allowing an easier rationalizing of all experimental data.

\section{Acknowledgments}

The work was supported by Università di Palermo and Ministero dell'Istruzione, dell'Università e della Ricerca (MIUR).

\section{Appendix A. Nomenclature}

A BDD

$c^{*}$ anodic surface

boron doped diamond

$i_{\text {app }} /\left(n F k_{\mathrm{m}}\right)$ Concentration of $R H$ that gives rise to a limiting current density $i_{\text {lim }}$ equal to the applied current density $i_{\text {app }}$ current efficiency for the abatement of an organic as defined in Eq. (2)

$C E_{\text {COD }}$ current efficiency for the abatement of COD as defined in Eq. (4)

$C E_{X} \quad$ local current efficiency for a given value of $x$

$C E^{\mathrm{OC}} \quad C E_{X}$ under oxidation reaction control

$C E_{a v}^{O C}$ average $C E^{O C}$ for organics present in the solution for a process under oxidation reaction control

COD chemical oxygen demand of the solution

$D$ diffusion coefficient of organic

$D_{a v} \quad$ average diffusion coefficient of organics present in solution

F $\quad$ Faraday constant $\left(96487 \mathrm{C} \mathrm{mol}^{-1}\right)$

FA formic acid

$h$ height of the channel which coincides with the inter electrodic gap

$i_{\text {app }} \quad$ applied current density

$i_{\mathrm{RH}} \quad$ current density for the oxidation of $\mathrm{RH}$

$i_{\mathrm{O}_{2}} \quad$ current density for the oxygen evolution reaction

$i_{\text {lim }} \quad n F k_{\mathrm{m}}[R H]_{X}$ limiting current density

$J \quad$ flux of the organic at the electrode

$k_{\mathrm{m}} \quad$ mass transfer coefficient

$L \quad$ length of the channel (and of the electrodes) as illustrated in Fig. 1

$n \quad$ number of electrons exchanged for the oxidation of $\mathrm{RH}$ to carbon dioxide or to a stable compound

Q charge passed during the electrolysis

$[R H]$ concentration of the organic species $R H$

$[\overline{R H}]_{X}$ average concentration of the organic $R H$ for a given value of $x$

$[R H]_{X}^{y=0}$ concentration of the organic $R H$ at the anodic surface for a given value of $x$

$[R H]^{\mathrm{b}} \quad$ concentration of $R H$ in the bulk of the solution for an electrolysis carried in macro cells

$[R H]^{*} \quad$ value of $[R H]_{x}^{y=0}$ which gives a current density for the $R H$ oxidation equals to the current density involved in the oxygen evolution reaction, e.g., value of $[R H]_{x}^{y=0}$ which gives $C E=50 \%$

$[R H]^{\prime} \quad[R H]_{x}-[R H]^{*}-c^{*}$

Sh $\quad 2 k_{m} h / D$ Sherwood number

$S h^{\propto} \quad$ Sherwood number after the entrance zones

$t \quad$ average residence time in the microfluidic reactor

$t^{*} \quad$ time necessary to decrease the concentration of the organic in the reactor to the value $c^{*}$ by an anodic process with $C E=1$

$t_{\mathrm{COD}}{ }^{*} \quad$ time necessary to decrease the COD in the reactor to the value $c^{*}$ by an anodic process with $C E=1$

$u_{a v} \quad$ average linear velocity of the flow in the cell in the $x$ direction

$u_{x} \quad$ linear flow velocity component along the direction $x$

$u_{y} \quad$ linear flow velocity component along the direction $y$

$V \quad$ volume of the cell

$x, y, z \quad$ coordinates as defined in Fig. 1

$X \quad$ abatement (e.g., conversion) of the organic as defined in Eq. (1)

$X_{\mathrm{COD}}$ abatement (e.g., conversion) of the COD as defined in Eq. (3)

W width of the channel (and of the electrodes) as illustrated in Fig. 1

Greek letters

$\delta \quad$ thickness of the stagnant layer in a macroreactor with turbulent fluidodynamic regime

$\Phi_{V} \quad$ volumetric flow rate 


\section{References}

[1] N. Kockmann, N. Kockmann, Advanced Micro and Nanosystems, Micro Process Engineering. Foundamentals, Devices, Fabrication and Application, 5, WileyVCH Verlag GmbH \& Co. KGaA, Weinheim, 2006, Ch. 1.

[2] D. Erickson, D. Li, Anal. Chim. Acta 507 (2004) 11.

[3] C.A. Paddon, M. Atobe, T. Fuchigami, P. He, P. Watts, S.J. Haswell, G.J. Pritchard, S.D. Bull, F. Marken, J. Appl. Electrochem. 36 (2006) 617.

[4] W.R. Vandaveer, S.A. Pasas, R.S. Martin, S.M. Lunte, Electrophoresis 23 (2002) 3667.

[5] V. Hessel, S. Hardt, H. Lowe, Chemical Micro Process Engineering. Fundamentals, Modelling and Reactions, Wiley-VCH Verlag GmbH \& Co. KGaAed, Weinheim, 2004, Ch. 1.

[6] K. Uchiyama, H. Nakajima, T. Hobo, Anal. Bioanal. Chem. 379 (2004) 375.

[7] P.S. Dittrich, K. Tachikawa, A. Manz, Anal. Chem. 78 (2006) 3887.

[8] P. He, P. Watts, F. Marken, S.J. Haswell, Electrochem. Commun. 7 (2005) 918.

[9] P. He, P. Watts, F. Marken, S.J. Haswell, Lab. Chip 7 (2007) 141.

[10] D. Horii, M. Atobe, T. Fuchigami, F. Marken, Electrochem. Commun. 7 (2005) 35.

[11] C. Amatore, M. Belotti, Y. Chen, E. Roy, C. Sella, L. Thouin, J. Electroanal. Chem. 573 (2004) 333.

[12] C. Amatore, A. Oleinick, O.V. Klymenko, I. Svir, Chem. Phys. Chem. 6 (2005) 1581.

[13] C. Amatore, O.V. Klymenko, I. Svir, Chem. Phys. Chem. 7 (2006) 482

[14] C. Amatore, O.V. Klymenko, A. Oleinick, I. Svir, Anal. Chem. 81 (2009) 7667.

[15] M. Thompson, O.V. Klymenko, R.G. Compton, J. Electroanal. Chem. 576 (2005) 333.

[16] J. Wu, J. Ye, Lab. Chip 5 (2005) 1344.

[17] C. Amatore, C. Sella, L. Thouin, J. Electroanal. Chem. 593 (2006) 194.

[18] O. Scialdone, C. Guarisco, A. Galia, G. Filardo, G. Silvestri, C. Amatore, C. Sella, L. Thouin, J. Electroanal. Chem. 638 (2010) 293.

[19] C.A. Martinez-Huitle, S. Ferro, Chem. Soc. Rev. 35 (2006) 1324.

[20] P. Canizares, R. Paz, C. Saez, M.A. Rodrigo, J. Environ. Manage. 90 (2009) 410.

[21] O. Scialdone, S. Randazzo, A. Galia, G. Filardo, Electrochim. Acta 54 (2009) 1210.

[22] M. Panizza, G. Cerisola, Electrochim. Acta 51 (2005) 191.

[23] O. Scialdone, A. Galia, G. Filardo, Electrochim. Acta 53 (2008) 7220.

[24] O. Scialdone, A. Galia, C. Guarisco, S. Randazzo, G. Filardo, Electrochim. Acta 53 (2008) 2095.
[25] P. Canizares, J. Garcia-Gomez, J. Lobato, M.A. Rodrigo, Ind. Eng. Chem. Res. 42 (2003) 956.

[26] O. Scialdone, S. Randazzo, A. Galia, Chem. Eng. J., submitted for publication.

[27] D. Gandini, E. Mahe, P.A. Michaud, W. Haenni, A. Perret, Ch. Comninellis, J. Appl. Electrochem. 30 (2000) 1345

[28] P. Canizares, J. Garcia-Gomez, J. Lobato, M.A. Rodrigo, Ind. Eng. Chem. Res. 43 (2004) 1915.

[29] M. Panizza, P.A. Michaud, G. Cerisola, Ch. Comninellis, J. Electroanal. Chem. 507 (2001) 206.

[30] A.M. Polcaro, M. Mascia, S. Palmas, A. Vacca, Ind. Eng. Chem. Res. 41 (2002) 2874;

M. Polcaro, S. Palmas, Ind. Eng. Chem. Res. 38 (1997) 1791;

A.M. Polcaro, A. Vacca, S. Palmas, M. Mascia, J. Appl. Electrochem. 33 (2003) 885.

[31] O. Scialdone, Electrochim. Acta 54 (2009) 6140.

[32] O. Scialdone, S. Randazzo, A. Galia, G. Silvestri, Water Res. 43 (2009) 2260.

[33] C. Comninellis, Electrochim. Acta 39 (1994) 1857.

[34] D.J. Pickett, Electrochemical Reactor Design, Elsevier Scientific Publishing Company, Amsterdam, 1977, p. 121.

[35] A. Renken, L. Kiwi-Minsker, in: N. Kockmann (Ed.), Advanced Micro and Nanosystems, Volume 5. Micro Process Engineering. Foundamentals, Devices, Fabrication, and Application, Wiley-VCH Verlag GmbH \& Co. KGaA, Weinheim, 2006, p. 173.

[36] J. Villermaux, Int. Heat Mass Transfer J. 14 (1971) 1963.

[37] A. Cybulski, J.A. Moulijn, Catal. Rev. Sci. Eng. 36 (1994) 179.

[38] R.E. Hayes, S.T. Kolaczkowski, Chem. Eng. Sci. 49 (1994) 3587.

[39] K. Elser, Schweiz. Bauzeitung 46 (1951) 641.

[40] O. Scialdone, A. Galia, L. Gurreri, S. Randazzo, Electrochim. Acta 55 (2010) 701

[41] H. Vogt, O. Aras, R.J. Balzer, Int. J. Heat Mass Transfer 47 (2004) 787.

[42] H. Vogt, Electrochim. Acta 38 (1993) 1427.

[43] A. Kawahara, P.M.-Y. Chung, M. Kawaji, Int. Multiphase Flow J. 28 (2002) 1411.

[44] S.R.A. De Loos, J. Van Der Schaaf, R.M. Tiggelaar, T.A. Nijuis, M.H.J.M. De Croon, J.C. Schouten, Microfluidics Nanofluidics 9 (2010) 131.

[45] J. Kristal, R. Kodym, K. Bouzek, V. Jiricny, Electrochem. Commun. 10 (2008) 204

[46] O. Scialdone, A. Galia, Synthetic diamond films preparation, electrochemistry, characterization and applications, in: E. Brillas, C.A. Martinez-Huitle (Eds.), Chapter 11, C., Wiley, in press. 